\title{
Sororidad entre mujeres mayores en Santiago de Chile. Un análisis a la luz de la gerontología feminista $^{1}$
}

\section{Constanza Gómez-Rubio}

(iD) https://orcid.org/0000-0002-8857-0694

Mujeres y Raíces, Oviedo - España

constanza@mujeresyraices.com

RESUMEN

Son recientes los estudios que abordan las relaciones entre mujeres al interior de organizaciones autogestionadas de personas mayores. Por ello, esta investigación cualitativa analiza los discursos de mujeres mayores de Santiago de Chile en torno a las relaciones que establecen entre ellas dentro de organizaciones comunitarias autogestionadas, y el vínculo que construyen con sus propias vejeces. Se realizaron dieciocho entrevistas a mujeres mayores entre $2016 y$ 2019, que fueron analizadas mediante análisis crítico del discurso. Los resultados refirieron a tres tópicos: la relevancia de lo colectivo en la vejez femenina, las prácticas de resistencia frente al control de la Iglesia y del Estado, y al hecho de ser mujeres viejas. El discurso de apoyo mutuo y sororidad resultan claves para comprender sus relaciones. Se resalta la importancia de producir modelos femeninos de vejez, que sirvan a las generaciones más jóvenes de mujeres.

Palabras clave: vejez femenina, sororidad, gerontología feminista, discurso, cuidados mutuos.

\footnotetext{
1 Este trabajo fue financiado por CONICYT PFCHA/ Doctorado en el extranjero 72160039.
} 


\title{
Sorority among older women in Santiago of Chile: An analysis in the light of feminist gerontology
}

\author{
ABSTRACT
}

Recent studies address the relationships between women within self-managed organizations of older people. For this reason, this qualitative research analyzes the discourses of older women in Santiago of Chile, around the relationships they establish between them, within self-managed community organizations, and the relationship they build with their own old age. 18 interviews were conducted with older women between 2016 and 2019, which were analyzed through critical discourse analysis. The results referred to three topics: the relevance of the collective in female old age, the practices of resistance against the control of the Church and the State, and the fact of being old women. The discourse of mutual support and sisterhood are keys to understanding their relationships. The importance of producing female role models of old age, serving the younger generations of women, is highlighted.

Keywords: Female old age, sisterhood, feminist gerontology, discourse, mutual care. 


\section{INTRODUCCIÓN}

Esperanza caminaba bajo el sol, pisando el cemento de las aceras desgastadas. Sus desniveles y socavones formaban parte del paisaje cotidiano del barrio. Al llegar a casa de Marcela, tocó el timbre y la esperó en la puerta. Con la mano intentaba tapar el fuerte sol que le quemaba la piel. La escasez de árboles era un problema en el sector, que todos los veranos se encarnaba en la piel de los vecinos. Al salir Marcela, caminaron juntas a la sede donde se reunía semanalmente la organización comunitaria en la que participaban.

Fueron las últimas en llegar. Las esperaban para comenzar la reunión. Rezaron un Padrenuestro y dieron la bienvenida a dos nuevas integrantes. De inmediato les explicaron la norma más importante del grupo: «Todas somos viejas y ninguna tiene ná. Solo nos tenemos a nosotras mismas, así que aquí nos cuidamos, nos apoyamos y nos queremos». Yo estaba ahí y muchas veces había sido testigo de cómo esas mujeres habitaban el mundo juntas, de cómo los vínculos entre ellas podían impulsar, fortalecer o resistir otras relaciones.

Me habían contado historias sobre la comunidad y cómo entre ellas se protegían ante situaciones peligrosas. Me hablaron sobre sus encuentros y desencuentros con la Iglesia, de cómo se manejaban con las diferentes instituciones del Estado. Me mostraron la dulzura de la vida, pero también la amargura del desamor y del dolor de la pérdida.

En este artículo deseo compartir parte de estas experiencias. Para ello, analizo - desde una perspectiva gerontológica feminista - los discursos de las mujeres mayores de Santiago de Chile en torno a las relaciones que establecen entre ellas dentro de las organizaciones comunitarias autogestionadas en las que participan y de la relación que construyen con sus propias vejeces.

Trabajé con una perspectiva gerontológica feminista, ya que orienta la mirada a los significados específicos que se otorgan al envejecimiento y la vejez femenina (Yuni y Urbano, 2008). Esto es especialmente relevante en Chile, donde el envejecimiento ha sido un proceso acelerado y heterogéneo (Huenchuan, 2018), el tercer país más envejecido de América Latina, con un 17,5\% de habitantes 
mayores de sesenta años y el que cuenta con una mayor esperanza de vida en la región (Acosta, Picasso y Perrotta, 2019). De esta población, el 56,6\% corresponde a mujeres (Ministerio de Desarrollo Social, 2017), que viven en promedio seis a ocho años más que los hombres, aunque lo hacen en peores condiciones (Flores y Garay, 2019; Organización Mundial de la Salud, 2021).

Su participación social también es más alta. Un $55,1 \%$ de estas mujeres participa en agrupaciones de adultos mayores $(25,8 \%)$ y en organizaciones territoriales (29,3\%) (Ministerio de Desarrollo Social, 2017). En este escenario, resulta prioritario ampliar los estudios sobre vejez, poniendo atención a las diferencias de género y a los contextos locales, desde un pensar situado (Lois, 2020), que supone trabajar en la producción de conocimiento de forma comprometida y responsable (García Dauder, 2003).

Por lo anterior, este artículo reporta hallazgos de una investigación cualitativa realizada entre los años 2016 y 2019 , en la que participaron dieciocho mujeres mayores de 60 a 78 años pertenecientes a dos organizaciones comunitarias autogestionadas de una zona urbana de Santiago de Chile.

Para comenzar, me aproximaré a las vidas de las mujeres mayores que participaron en la investigación. Posteriormente, compartiré la metodología, que cuenta con un subapartado de retos y dificultades en la investigación y otro de estrategia analítica discursiva. Luego, abordaré los hallazgos, y finalmente, plantearé algunas reflexiones finales acerca de los resultados presentados.

\section{SITUANDO LAS VIDAS DE LAS MUJERES MAYORES EN LA INVESTIGACIÓN}

En Chile, ha existido una tendencia a construir a las personas mayores desde la vulnerabilidad y pasividad (Thumala, Arnold, Massad y Herrera, 2015), colocando a la vejez bajo un manto oscuro de significaciones sociales. Para transformar este escenario, es necesario comprender las vidas de estas personas como tiempos vividos, experiencias y vínculos que adquieren sentido en el tejido social.

Desde esta óptica, se analiza la vida de las mujeres mayores que participaron en la presente investigación. Ellas llevaban más de medio siglo conociéndose. Llegaron juntas en la década de 1960 al terreno en el que hoy viven. Sus circunstancias eran diversas: algunas eran aún adolescentes y solteras, otras adultas y casadas, pero todas provenían de la pobreza extrema de Santiago. Ahí, en ese terreno, construyeron sus casas y forjaron la comunidad, gracias al apoyo mutuo y la autogestión. 
Durante la dictadura cívico-militar (1973-1990) sus vidas sufrieron grandes impactos. Uno de ellos fue la imposición del experimento neoliberal chileno, que supuso la privatización de los derechos básicos, entre ellos las pensiones. Se instauraron las Administradoras de Fondos de Pensiones (AFP), donde todas las mujeres cotizaron (Garretón, 2012). Desde la primera década del siglo XXI, las mujeres que se jubilaban por este sistema debieron afrontar el hecho de que, pese a haber trabajado toda su vida, las pensiones eran significativamente menores a lo esperado, lo que generó que muchas debieran seguir trabajando o dependieran económicamente de otra persona, habitualmente de un hombre (Gómez-Rubio, Zavala-Villalón, Ganga-León, Rojas y Álvarez, 2016).

Otro impacto de la dictadura y del experimento neoliberal fue el cambio de la concepción de las relaciones humanas. No solo se buscaba modificar la economía, sino también la cultura, la subjetividad y los vínculos entre las personas. Se exaltó el individualismo - por sobre la colectividad, la competitividad sobre la ayuda mutua-y la propiedad privada sobre el bien común y lo público (Garretón, 2012).

Todo lo anterior generó cambios importantes en la vida cotidiana de las mujeres, como preocupaciones por la subsistencia y problemas de salud física y mental. Para enfrentar esto, muchas de ellas se agruparon en organizaciones comunitarias autogestionadas, entendidas como aquellas que se conducen con autonomía a partir de intereses y necesidades consensuadas comunitariamente (Vera y Ceballos, 2021), lo que no las limita a la autosuficiencia económica, sino que implica prácticas de apoyo mutuo y solidaridad (Méndez y Vallota, 2006).

Las mujeres que participaban en este tipo de organizaciones asumían una responsabilidad individual frente a la colectividad, tomando sus propias decisiones con cierta autonomía de los agentes externos (León y Montenegro, 1999), pero manteniendo una relación con estos, en tanto parte activa de un tejido social más amplio.

\section{Relaciones de sororidad y participación social en la vejez}

Las organizaciones comunitarias autogestionadas contribuyen a la mejora de la calidad de vida de las mujeres mayores que participan en ellas, sin descuidar la atención física y psicológica en los casos que se requiera (Irarrázaval, Streeter y Salas, 2018). Entiendo «calidad de vida» como un indicador cualitativo que «nos habla de vidas particulares, de lo cotidiano, de relaciones, de experiencias vivenciales que son únicas e irrepetibles, de sentimientos, de deseos, etc.» (Navarro, 2017, p. 90). Esto se reflejaba, por ejemplo, en la reciprocidad de 
la ayuda psicológica que se brindaban colectivamente, que permitía que las experiencias dolorosas fueran más transitables. La relación entre mujeres que implica una alianza, un reconocimiento y un apoyo mutuo se conoce como sororidad (Lagarde, 2006). Así: «Es una experiencia de las mujeres que conduce a la búsqueda de relaciones positivas y la alianza existencial y política [...] para contribuir con acciones específicas a la eliminación social de todas las formas de opresión» (Lagarde, 2006, pp. 3-4).

Esta relación de apoyo entre mujeres comienza a gestarse con la socialización en los vínculos que aprenderían en sus infancias, y que en la vejez facilitaría la creación de redes de ayuda mutua (Freixas, Luque y Reina, 2012). Según García (2013), muchas de estas redes nacerían en organizaciones comunitarias vecinales, que son las formas más concretas de organización en los sectores populares.

La participación en este tipo de organizaciones suele darse ante la escasa protección social y la imposibilidad económica de acceder al mercado (Paura y Zibecchi, 2014; Zibecchi, 2013), ya que las redes que ahí gestan las mujeres mayores se orientan a la resolución de problemas que no podrían resolverse de otras formas. Pérez-Sánchez, Rábago-De Ávila, Guzmán-Ortiz y Zamora-Pérez (2018), sostienen que las mujeres mayores construyen redes de sororidad que son centrales en su envejecimiento, aunque las autoras reconocen que responden más a un deseo que a acciones concretas.

En sectores populares, la sororidad y la participación de mujeres mayores en organizaciones comunitarias se convierten en un sostén de los tejidos sociales locales. Sin embargo, también se ha evidenciado que la clase social puede mermar la participación comunitaria de las personas mayores. Por ejemplo, Enríquez (2014) indica que la pobreza en grandes ciudades reduce la reciprocidad vecinal. De igual forma, la inseguridad en las condiciones de vida merma la participación social de las personas mayores (Majón-Valpuesta, Pérez-Salanova, Valverde y Molina, 2021). Otro estudio plantea que las mujeres mayores de clases bajas no disfrutan la participación si esta conlleva algún costo económico (Repetti y Calasanti, 2017).

La participación social y la capacidad de acción de las mujeres mayores nos habla, por una parte, de la agencia sobre sus contextos locales, y por otra, de las prácticas de resistencia que podrían ejercer en estos. En consecuencia, dado los diferentes contextos históricos-culturales específicos, no es posible definir unívocamente la agencia y la resistencia femenina (Cañas, 2018; Mahmood, 2005).

Mahmood (2005) argumenta que la «erudición» feminista ha ignorado modalidades de agencia y de resistencia que quedan fuera de la política subversiva. Por 
lo tanto, si aprendemos a leer las resistencias locales y cotidianas en estructuras de poder particulares, podremos conocer las transformaciones en las relaciones sociales, que influyen en quienes ejercen resistencias y entre quienes ejercen el poder (Mahmood, 2005). En esta línea, para efectos de este artículo, se entenderá agencia como una capacidad de acción voluntaria (Cañas, 2018), y resistencia como una oposición a una estructura o relación de poder (Mahmood, 2005).

\section{METODOLOGÍA Y PROCESO INVESTIGATIVO}

La investigación fue de carácter cualitativo, entendiéndose esto como una actividad que ubica a la investigadora en el fenómeno estudiado. Para ello, utiliza un conjunto de prácticas materiales y de interpretación que visibilizan y transforman el mundo (Denzin y Lincoln, 2005), a la vez que construye sentidos intersubjetivos situados sociohistóricamente (Alonso, 1998).

En este estudio me centré en los discursos de dieciocho mujeres mayores que participaban en dos organizaciones comunitarias autogestionadas. Llegué a ellas por una informante clave de la comunidad de vecinos, a quien había conocido con anterioridad. Ella me colocó en contacto con las organizaciones de personas mayores que accedieron a participar en la investigación.

Utilicé una muestra por conveniencia, ya que en un comienzo trabajé con las participantes que tenían más facilidad de acceso. Luego, la muestra fue seriada, dado que la participación de las mujeres se realizó a partir de la información producida por quienes ya habían sido seleccionadas anteriormente. En conjunto trabajé de forma progresiva, ya que ajusté la muestra en la medida que avanzaba el estudio; así, las nuevas entrevistas ayudaron a focalizar el muestreo (MartínCrespo y Salamanca, 2007).

Realicé entrevistas abiertas semidirectivas, considerando una pauta de temas para abordar con cada entrevistada (Valles, 1999), pero orientadas de forma general a las experiencias de vida, con especial atención a la vejez. Duraron entre sesenta y noventa minutos, pero en tres casos realicé más de una sesión. La colaboración de las mujeres mayores en la investigación estuvo dada por: (i) su deseo y voluntad de participar; (ii) tener más de sesenta años; (iii) llevar un mínimo de seis meses en la organización, para poder hablar detalladamente sobre esta, y (iv) pertenecer a la comunidad vecinal.

Por otra parte, las mujeres tenían una participación en dos organizaciones comunitarias: nueve de las entrevistadas pertenecían a la Organización 1 y las 
otras nueve a la Organización 2. Ambas estaban ubicadas en la comuna de Peñalolén, que forma parte de la provincia de Santiago, en la Región Metropolitana de Chile. Se encuentra en los pies de la precordillera de Los Andes y cuenta con un $10,3 \%$ de población mayor de 65 años (Instituto Nacional de Estadística, 2017). Se caracteriza por contar con patrones de reproducción de desigualdad social, ya que existen dos perfiles socioeconómicos opuestos. El primero, es el sector antiguo de Peñalolén, altamente envejecido, con el 50\% de su población sin escolaridad completa y económicamente vulnerable. El segundo - el sector nuevo- con una población más joven, con mayores niveles de escolaridad y de alta capacidad adquisitiva (Arias, Lucero, Lores, Florín, Jorquera, Jofré y Villegas, 2020).

Existen 146 organizaciones de personas mayores (Ilustre Municipalidad de Peñalolén, 2021). De ellas, para esta investigación se trabajó con dos. En la Organización 1 participaban veinte personas, entre mujeres y hombres. Era un proyecto que nació alrededor de la iglesia del barrio y que tenía dos años de vida. Las participantes se reunían de lunes a viernes y aquellas que tenían dificultades de movilidad disponían de traslado. Algunas contaban con tareas asignadas como la preparación de comida - y otras aportaban con lo que podían, sobre todo cuando tenían dificultades físicas.

La Organización 2 tenía treinta años de existencia, contaba con 36 participantes y desde el comienzo fue dirigida por mujeres. Pese a que en sus orígenes la iglesia les había facilitado un pequeño terreno a modo de préstamo, en la actualidad ya no se encontraban ahí. En el año 2012 un nuevo párroco redistribuyó los espacios y dejó sin sede física a la organización. Esto generó una gran molestia de las mujeres hacia la iglesia, ya que no fueron consultadas ni avisadas del cambio: simplemente un día les informaron que no podían volver. Dada esta situación, buscaron un nuevo lugar, lejos de la iglesia, donde comenzaron a reunirse una vez a la semana.

\section{Retos y dificultades en proceso investigativo con mujeres mayores}

Para realizar las entrevistas, me situé como una mujer que carga su propia historia, sus deseos y emociones, lo que facilitó una relación de confianza con las participantes. No obstante, mi posición como investigadora marcaba diferencias importantes. La educación y la clase fue la primera diferencia que se me hizo presente. Muchas mujeres no sabían leer ni escribir y nunca habían pisado una escuela. Ante ellas, mi rol de investigadora no era importante. Ahí lo relevante era 
la ayuda mutua y las redes de sororidad que tejían a diario. Por tanto, mientras yo me manejara dentro de estas formas o de esta norma, la diferencia podía ser tratada.

Pese a lo anterior, la diferencia más difícil de sortear fue la edad. Existía una brecha etaria de al menos treinta años que las entrevistadas me hacían notar con comentarios y preguntas, como: «¿Cuántos años tienes?»o «Eres como mi nieta». Esto llevó a preguntarme cómo podía trabajar la vejez desde mi mediana edad, en qué aportaba mi posición y mirada a la comprensión de la vida de las mujeres mayores, o cómo se podía materializar el feminismo en mi relación con las mujeres mayores.

Para abordar estas preguntas y diferencias, recurrí a la gerontología feminista, que estudia las experiencias de las mujeres mayores utilizando marcos de referencia feministas (Hooyman Ray, Browne y Richardson, 2002). Pone el énfasis en las relaciones de poder y en todo aquello que dificulta la libertad de las mujeres mayores (Freixas, 2008; Freixas et al., 2012). También analiza los significados de la vejez femenina y nos muestra el androcentrismo presente en el discurso científico y en las representaciones populares sobre ellas (Leyra y Roldán, 2013).

Desde este marco, si quería trabajar desde la gerontología feminista, debía considerar, al menos, tres aspectos: el primero, evitar los sesgos androcéntricos en la investigación, tanto en el trabajo directo con las mujeres como en su escritura; el segundo, contar con una alta sensibilidad hacia sus vidas, relaciones y contextos; y el tercero, colocarlas en el centro del proceso investigativo, siendo consciente de mi lugar frente a ellas.

Al reflexionar sobre la edad desde esta perspectiva, pensé que, si ellas me ofrecían parte de sus vidas, yo también debía hacerlo. De esta forma, compartí aspectos personales que terminaron por validarme frente a sus años de experiencias. Un punto en común que sirvió de puente entre ellas y yo fue la maternidad, que no eliminó la interpelación a mi edad, pero suavizó la diferencia y me posicionó como interlocutora dentro de un intercambio recíproco. Este intercambio generó un clima de confianza fundamental para que las mujeres compartieran parte de sus experiencias y participaran de forma activa en la evaluación del análisis de la información producida en el trabajo de campo, ya que pudieron modificar aquello con lo que no estaban de acuerdo y negociar entre ellas cuestiones esenciales de sus vidas. 


\section{Estrategia de análisis crítico del discurso}

Trabajé con análisis crítico del discurso (ACD), que estudia cómo la desigualdad y el abuso del poder son producidos, reproducidos y combatidos por el habla en un contexto social específico (Van Dijk, 2009). Lo hice desde la perspectiva de Norman Fairclough (2008), que entiende la relación entre discurso y estructura social como dialéctica, enmarcada en contexto histórico. Los discursos están constituidos y son constituyentes de elementos materiales de lo social. Por lo tanto, son una forma como podemos mantener y promover ciertas relaciones sociales (Iñiguez-Rueda, 2003).

En este sentido, el ACD tiene un carácter fundamentalmente político, donde la voz crítica viene dada por hacer visible la relación de las cosas, en la interdependencia continua entre los compromisos políticos y los intereses investigativos (Wodak, 2003). Por ejemplo, en algunos discursos de amor y ternura que colocan a las personas mayores en una posición de inferioridad a través de estilos de habla condescendientes, manejo de lenguaje directivo y disciplinario (Coupland, Coupland y Giles, 1991), o patrones infantiles de comunicación (Marsden y Holmes, 2014).

Consideré las entrevistas como un corpus textual unificado. En una primera lectura me familiaricé con el material, y en una segunda, codifiqué algunos contenidos explícitos del texto. Esto me proporcionó una visión más completa de los datos.

Luego, realicé un relato argumentativo que contuvo las diferentes posiciones de las participantes y los argumentos más utilizados por ellas. Con esto creé subcategorías provisionales que me sirvieron para organizar la información y reforzar la importancia de ciertos temas. Posteriormente, seleccioné las citas que analicé, colocando énfasis en los siguientes aspectos discursivos: significaciones (semántica), uso práctico del lenguaje (pragmática); recursos retóricos utilizados; estrategias de construcción discursiva y su posición social en el discurso.

Finalmente, el análisis fue leído por las participantes de la investigación y por otros y otras investigadoras de diferentes instituciones, lo que llevó nuevamente a una relectura del cuerpo textual, para incluir nuevas interpretaciones.

\section{HALLAZGOS}

Los hallazgos que se presentan a continuación son una muestra del ACD realizado. Para organizar el análisis se establecieron tres ejes: de lo individual a lo 
colectivo y del mercado a lo comunitario en la vida de mujeres mayores; dinero y autogestión: prácticas de resistencia frente a la Iglesia y el Estado, e infantilización y adultización: vínculo con la vejez propia.

Se seleccionaron las citas más representativas y se identificaron de la siguiente forma: nombre ficticio asignado, edad de las participantes y organización a la que pertenecían. Los énfasis que las mujeres mayores colocaron al relatar ciertas experiencias fueron subrayados en las citas correspondientes.

De lo individual a lo colectivo y del mercado a lo comunitario en la vida de mujeres mayores

Este eje abordó la construcción de las relaciones establecidas entre las mujeres mayores al interior de sus organizaciones comunitarias, a partir de la diferenciación de espacios:

Me olvido de mi casa, me olvido que tengo familia, o sea, para mí existe solamente $[\ldots]$ porque uno se ríe, conversa y comparte $[\ldots]$ porque uno en la casa es como un ogro, y allá es como la ovejita [risas], iporque se siente diferente! (Esperanza, 73 años, organización 2).

La afirmación realizada por Esperanza nos habla de la desconexión con el espacio doméstico, que podríamos deducir como problemático por la analogía «uno en la casa es como un ogro». El uso de la figura del ogro - para caracterizar a una persona solitaria, de mal aspecto y carácter - resalta el contraste con la ovejita: un animal dócil, que vive gregariamente con sus congéneres. Esta comparación muestra cómo la individualidad es asociada a lo doméstico, mientras que la colectivización a lo comunitario, espacio relevante en la vida de las mujeres, que se desmarca de la tradicional familiarización heteropatriarcal como soporte ideológico en Chile.

En la colectividad se tejen los cuidados mutuos, que son actos recíprocos $\mathrm{y}$ equitativos centrales en las vidas interdependientes de las mujeres mayores, basados en estrategias de afrontamiento compartidas y el manejo de códigos de subsistencia comunes. Así, el discurso de los cuidados se distancia de la representación del cuidado individual.

Desde esta perspectiva, los cuidados mutuos forman parte fundamental de la calidad de vida de las mujeres (Navarro, 2017), ya que, entre otras cosas, producen satisfacción psicológica, contrastando con el sentir generado en el espacio doméstico. En consecuencia, lo colectivo se constituye mediante los cuidados, como una fuente de protección psicosocial en la vejez femenina. 
La existencia de cuidados mutuos no excluye la presencia de otros discursos que conciben los cuidados de forma diferente, como el biomédico:

Todos vamos a este estado de dependencia. Yo ahora, que tengo 65 , me muevo y hago mis cosas, pero a los 75 ya la gente no funciona bien, porque las neuronas están dañadas y, al final, te terminan cuidando como una guagua (Mirta, 65 años, Organización 1).

La construcción de la vejez se realiza en términos de edad y funcionamiento, bajo el supuesto de un declive inevitable de la vida y del deterioro de la calidad de vida, que se desprende de la afirmación «te terminan cuidado como una guagua». En Chile, se utiliza la palabra aimara guagua como sinónimo de bebé, que en el contexto inmediato de la frase (el texto que la precede), puede dar cuenta que la comprensión del cuidado como actividad unidireccional, vale decir, una persona activa que brinda cuidados a otra, receptora de dichos cuidados.

La analogía con la "guagua» habla de una mirada pasiva y una supuesta dependencia del final de la vida, dado que una guagua solo se comunica a través del llanto cuando demanda alguna necesidad, estando su vida a merced de los cuidados de sus tutores o tutoras. Esta perspectiva es potenciada por la explicación biológica: «Pero a los 75 ya la gente no funciona bien, porque las neuronas están dañadas. Es decir, el deterioro partiría por una edad determinada y no por las condiciones particulares de cada quien, lo que implicaría que el declive es un camino inevitable para todas las personas: «Todos vamos a este estado de dependencia».

El discurso biomédico se encuentra altamente difundido, como es posible apreciar en el relato de Mirta, pero su acceso es restringido y limitado, lo que podría reproducir desigualdades y discriminaciones (Fairclough, 2008) asociadas con ciertos grupos de la población, como las personas mayores de 75 años.

No obstante, también existe una producción discursiva alternativa:

También me siento cuidada, porque yo estoy dando, pero estoy recibiendo. Es un cuidado pa'l cuerpo, yo vengo acá, muevo mis manos, mis brazos, me ayuda con mi ser, me siento querida aquí (Sonia, 60 años, Organización 1).

La reciprocidad tensiona el discurso biomédico y el modelo unidireccional de los cuidados, analizados anteriormente. Asimismo, amplía su concepción de lo puramente corporal a la dimensión subjetiva, lo que se explicita en la cita de Sonia: «Me ayuda con mi ser, me siento querida aquí». Así, sentirse querida alude a una dimensión afectiva y relacional que refuerza la mutualidad en los cuidados. 
En el habla, la participante destaca la palabra «recibiendo» para enfatizar la idea de que los cuidados son compartidos entre personas iguales, que comparten un entorno similar donde pueden sentirse importantes las unas para las otras, dando espacio a un discurso de interdependencia. Esta concepción de las relaciones es la base de la sororidad que tejen cotidianamente, que incluso potencia procesos de cura y rehabilitación:

Con la trombosis perdí el habla, pero aquí aprendí a hablar de nuevo. Fue gracias a las viejas que me cuidaron [silencio de cuatro segundos], entre todas las viejas nos cuidamos [silencio de dos segundos], las penas las compartimos (Alba, 75 años, Organización 1).

Es interesante destacar que la participante no utiliza un léxico relacionado con la amistad, sino con el compañerismo. Esta diferenciación semántica es relevante, ya que la sororidad — como sostiene Lagarde (2006) — refiere a la alianza política y apoyo entre mujeres que no necesariamente son amigas. En este marco se desarrolla la cita de Alba, quien atribuía a las compañeras el logro de volver a hablar después de haber sufrido una trombosis; es decir, no como un proceso de rehabilitación individual, sino colectivo.

El tratamiento de la trombosis da cuenta de cómo la sororidad, en tanto acto político que se sostiene en el discurso feminista, no necesariamente implica la amistad para ejercer su fuerza, sino que puede transformar las relaciones y la vida de las mujeres mayores. En esta línea, existe un reconocimiento explícito al apoyo de otras mujeres, mediante un lenguaje generizado femenino que facilitaría la reproducción de nuevas alianzas sororas para hacer frente a las estructuras de poder.

Dentro del lenguaje generizado, se encuentra la palabra viejas, que la participante utiliza de un modo emotivo, sin hacer uso de diminutivos ni de recursos retóricos de reducción del sujeto, como la infantilización. «Vieja» remite directamente a la vejez, sin insinuaciones que suavicen la experiencia, dejando de lado el estigma de ser una palabra inapropiada y peyorativa. En este sentido, Freixas (2008) plantea que todos los eufemismos lingüísticos utilizados para llamar a las viejas y a los viejos desvían la atención del foco principal, que es el valor socialmente otorgado a la vejez. Así, un primer paso para hablar de ellas es nombrarlas como tal: «viejas».

El relato de Alba muestra la socialización de género, reflejada en la importancia de las relaciones humanas y en la construcción de un espacio para compartir el dolor, lo que se aprecia en la frase «las penas las compartimos» y en la siguiente cita: 
Entonces uno se siente bien, muchas tienen pena, ahí se comparte [...]. Todas son una (Marcela, 75 años, Organización 1).

El apoyo entre mujeres permite compartir las penas y tristezas. Implícitamente nos encontramos con la interdependencia y los cuidados mutuos, que nos llevan a pensar en una perspectiva feminista - aunque no explícita-, que se refuerza con la expresión «todas son una», para dar cuenta de que la ayuda mutua no se crea a partir de muchos «yo», sino de un colectivo de reciprocidades.

Pese a lo anterior, la interdependencia y la sororidad se fisuran cuando se abordan temas financieros. Ambas organizaciones cuentan con un aporte monetario voluntario bajo la lógica de la ayuda mutua: las que tienen más, aportan mayores montos para ayudar a las que tienen menos recursos. Empero, dicha lógica entra en disputa con el discurso mercantil e individualista, fuertemente arraigado en la subjetividad de quienes han sufrido los efectos del experimento neoliberal chileno (Garretón, 2012):

Todos los meses aporto cinco mil pesos, todas debería también [...] Lo quieren todo gratis (Ernestina, 78 años, Organización 1).

Yo creo que la solución pa'la cosa de la plata, es que la que paga más tenga más beneficios y la que pague menos, tenga menos (Anita, 66 años, Organización 2).

Se desprende un interdiscurso individualista-mercantil en la comprensión de los procesos comunitarios, en las expresiones «lo quieren todo gratis» y «la que paga más tenga más beneficios y la que pague menos, tenga menos», ya que hace pasar de la ayuda mutua (con el aporte voluntario) a lo mercantil (deber pagar por lo que se tiene o se usa). Este tránsito da cuenta de la dificultad de pensar la vida fuera de los márgenes del mercado.

Dentro del discurso individualista-mercantil, las participantes de posicionan como consumidoras, en una lógica clientelar que cuestiona el acceso a beneficios a las mujeres que daban menos dinero del esperado. Así, por ejemplo, Anita utiliza el verbo «pagar» como si de una deuda o deber se tratara, y Ernestina alude a la gratuidad como un reproche hacia quienes no aportan con dinero.

La gratuidad es un tema en tensión en el contexto chileno: para algunos grupos más conservadores significa un aprovechamiento hacia la sociedad y el Estado, mientras que para sectores más progresistas tiene que ver con los derechos fundamentales. En este sentido, la exaltación de la propiedad privada por sobre el bien común (Garretón, 2012) a menudo provoca que el solo hecho de sospechar su presencia genere una reacción negativa. 


\section{Dinero y autogestión: prácticas de resistencia frente a la Iglesia y el Estado}

Aquí me interesa mostrar las relaciones que establecen las mujeres con la Iglesia y el Estado como dos instituciones relevantes para ellas. Concretamente, me centraré en las prácticas de resistencia adoptadas mediante la autogestión.

Un aspecto central en la autogestión de las organizaciones es la administración del dinero que se lleva a cabo por las mujeres mayores. No obstante, cuando esto es cuestionado por algún agente externo, se crean prácticas de resistencia colectiva - vale decir, una oposición consciente ante una relación de poder — en el contexto específico (Mahmood, 2005):

La Iglesia quería meterse mucho en las cosas de nosotros, entonces el padre quería que nosotros no manejáramos plata, quería que esa plata se la pasáramos a ellos, y ellos iban a manejar nuestra plata. ¡Entonces nosotros dijimos que no! La plata era de nosotros, nosotros veíamos cómo gastábamos la plata (Dolores, 70 años, Organización 2).

Cambió el cura y nos dio una patada en el traste. Un día nos dijo que teníamos que irnos, así que tuvimos que hacerlo todo nosotras, nosotras nos movimos. ¡Hasta hablamos con la alcaldesa! (Cristina, 76 años, Organización 2).

La organización utilizaba un espacio exterior de la iglesia del barrio, que turnaba por días con otras organizaciones. Sin embargo, tras un conflicto por la gestión del dinero, la relación de las mujeres con la Iglesia cambió.

Por una parte, Dolores posiciona a la Iglesia como una institución de intromisión a partir de la afirmación «la Iglesia quería meterse mucho en las cosas de nosotros». Lo hace mediante un recurso retórico de nomilización, vale decir, de la transformación nominal de actores sociales específicos en nombres generales. Por ejemplo, al comienzo de la cita, en lugar de aludir directamente al sacerdote (actor social), alude a la Iglesia, invisibilizando el actuar de este.

Posteriormente, la estrategia retórica cambia y se concreta el discurso en la figura del «padre» y su rechazo personal a la autogestión de las mujeres, desprendido de «quería que nosotros no manejáramos plata». Luego, este rechazo se transforma en un deseo por gestionar el dinero: «Ellos iban a manejar nuestra plata». En este contexto, la Iglesia se significa mediante figuras masculinas - a partir de la utilización del pronombre «ellos»—-para referirse a quienes la manejan.

Debido a lo anterior, la agencia, en tanto capacidad de acción de las mujeres (Cañas, 2018), se coloca en juego en la explícita negativa a transferir el control de sus finanzas a la Iglesia. Esta oposición se manifiesta como una práctica 
de resistencia ante la Iglesia como institución, y también a los hombres que la representan.

Por otra parte, hay participantes que delimitan el problema a una figura particular. En la segunda cita, Cristina utiliza la expresión «nos dio una patada en el traste» para explicar que el nuevo párroco las echó del lugar de mala forma, ya que - literalmente - la expresión significa un golpe en el trasero.

El relato muestra otro ejercicio de agencia, que fue la búsqueda y construcción de una nueva sede para la organización. El verbo «mover», en la afirmación «nosotras nos movimos», explica este ejercicio de acción que las llevó a negociar con la autoridad máxima del municipio. La participante pone énfasis en el sustantivo alcaldesa para dar legitimidad a su agencia, ya que conoce la fuerza que esta tiene en su accionar colectivo.

De igual forma, estas mujeres también tienen prácticas de resistencia frente al Estado, otra institución de control y poder patriarcal:

Si entra alguien es decisión de la asamblea si acepta más jóvenes como socios cooperadores, pero ellos no tienen derecho a paseo, nada de eso, pero si yo no puedo, mi puesto se lo pueden ceder a ellos [...] pero sin conocimiento del Estado, porque si sabe que nosotros llevamos una persona más joven, nos castiga (Teresa, 66 años, Organización 2).

Para acceder al financiamiento de proyectos, el Estado coloca las normas sobre el funcionamiento de las organizaciones comunitarias autogestionadas, lo que se relaciona con el ejercicio del poder sobre las diferentes vejeces que solicitan recursos económicos. Pero ¿cuáles son las vejeces que necesitan de tales recursos? Aquellas que carecen de medios económicos para sustentar cualquier actividad extraordinaria. Por consiguiente, el discurso dominante del Estado no se dirige a una vejez homogénea, sino a las vejeces pobres.

Las mujeres comprenden la norma que coloca el Estado. Ello se puede inferir por el énfasis en la afirmación «nos castiga». No obstante, la agencia y la resistencia se imponen, pues son ellas quienes tienen la última palabra. Deciden si admiten o no a personas más jóvenes, aceptando las consecuencias que esto puede conllevar.

La resistencia ante el Estado también se encuentra en el uso estratégico de la información que entregan a los organismos públicos. Producen un discurso local referido a la mantención de la autonomía mediante el manejo del sistema. Para tener dicho manejo, construyeron conocimientos a lo largo de sus vidas, que se reflejan en las diferentes estrategias utilizadas como las formas de presentar las postulaciones a proyectos. 
Debemos considerar estos actos de agencia y resistencia como centrales para desestigmatizar a las mujeres mayores de sectores populares y dejar de verlas como víctimas de sus condiciones sociales. En ellas existen conocimientos y prácticas invisibilizadas que resultan esenciales para su subsistencia, y que podrían servir, como modelos femeninos de vejez, a las mujeres más jóvenes.

\section{Infantilización y adultización: vínculo con la vejez propia}

En este eje presento el vínculo que realizan las mujeres mayores con sus propias vejeces y las tensiones que se evidencian.

Por una parte, se entiende el tiempo a partir de la edad cronológica como dato objetivo y estructurante del ciclo vital. Así, a más edad, mayor sería el deterioro y más cercanía con el fin de la vida, lo que se relaciona con algunos principios más tradicionales del discurso biomédico. En paralelo, también surge una construcción de la vejez más reflexiva en torno al paso del tiempo, tanto en lo que respecta al contenido como a la forma de expresión, mediante los silencios:

Yo ayer tenía quince años, así de rápido. Yo ahora veo a mis nietos [silencio de tres segundos] tengo nietos de dos, tres años, y de repente los miro [silencio de dos segundos] y mis hijos eran así y tal cual, ayer (Asunción, 61 años, Organización 1).

Se me fue la vida cuidando [silencio de cinco segundos], ahora veo que no debí trabajar tanto [silencio de tres segundos], ¿pa' qué? [suspiro], la vida pasa muy rápido. Aprovecha de vivir harto (Consuelo, 78 años, Organización 1)

Asunción sitúa la edad cronológica como referencia de tiempo y como base del relato. Utiliza el número de años para reforzar el sentir del paso del tiempo que, unido al uso de la palabra «ayer» y a la hipérbole «así de rápido» — cuya fuerza aumenta con el énfasis que coloca en la expresión-, intensifican el sentir de la experiencia. No obstante, el uso del «ayer» en el inicio y término de la cita muestra una inexactitud en la referencia al pasado que, junto a los silencios, producen una impresión de reflexión en quien la escucha.

Asimismo, la participante menciona a sus hijos y nietos para mostrar, mediante una comparación implícita, la oposición de su vejez a la niñez y a su propia juventud pasada. En este sentido, la vejez es definida como contraria a la juventud y no como una integración vital.

Por su parte, Consuelo realiza una evaluación de su vida centrada en el tiempo dedicado al trabajo de cuidado. Se realiza la pregunta retórica «¿pa'qué?», que se 
dirige al sentido que esto tuvo en la vida, lo que se ve reforzado por los silencios y por el suspiro, que también pueden tener como efecto la empatía de la audiencia y aportar profundidad en torno a lo relatado. Asimismo, la participante me interpela en tanto mujer más joven: «Aprovecha de vivir harto», ya que la vida sería muy corta. Me incorpora en su discurso en tanto interlocutora para legitimar el argumento, a la vez que realiza una invitación a pensar la vida desde la finitud, a partir de la emocionalidad del relato.

Otro aspecto en la construcción de la propia vejez era su oposición a la actividad:

Nunca me había sentido vieja, que estaba vieja, ¡no! Jamás. Era bien activa, ¡harta fuerza!, porque eso es lo que tenía que hacer toda mi vida, fuerza. Y me [silencio de cinco segundos] ese día me miré al espejo [silencio de cuatro segundos] y me vi que estaba vieja [silencio de siete segundos] y me sentí vieja [silencio de cinco segundos] a base de que, ver que [silencio de tres segundos] mi marido se iba con una mujer joven (Leonor, 75 años, Organización 2).

Leonor vivió la infidelidad de su marido, lo que la llevó a experimentar la vejez de una forma dolorosa. Esta se le presentó en su propio reflejo en el espejo y en la nueva pareja del su marido, una mujer más joven. Literalmente lo explica a partir de la visión de un cuerpo viejo, que resultó ser el suyo.

Las reiteradas pausas tornan el relato reflexivo. La mirada de sí misma transita, indirectamente, hacia la mirada masculina. Se posiciona en un extremo del binarismo juventud/vejez y sitúa a la otra mujer en el extremo opuesto, atribuyéndole la responsabilidad de lo sucedido.

Por una parte, encontramos el discurso y la ideología heteropatriarcal, que da un valor supremo a la juventud y significa la vejez como una pérdida de la feminidad, actuando sobre los cuerpos de las mujeres viejas y desvalorizándolos, tanto ante sus propios ojos como ante los ajenos. Así, el problema de Leonor queda relegado a un terreno construido, tradicionalmente, dentro de «lo femenino».

Una segunda forma de construir la vejez como opuesta a la actividad es mediante la autonomía:

Todavía puedo hacer muchas cosas. Quizás cuando esté más vieja y no sirva pa' na' me vaya a encerrar a un lugar de abuelitas pa' estar sentada sin hacer nada (Esperanza, 73 años, Organización 2).

El relato se focaliza en la autonomía de la participante, desprendida de la afirmación «todavía puedo hacer muchas cosas». El verbo «hacer» es clave 
para comprender el sentido de la cita que, en su primera parte, confiere valor a la funcionalidad individual - ya que la participante refiere a la relación con su propia vejez-. Este valor se puede relacionar con el binomio autosuficienciadependencia, que borra la heterogeneidad de acciones que las mujeres mayores pueden desplegar en sus vidas cotidianas, y la ejecución, con diferentes matices, de su agencia, según sea su contexto (Cañas, 2018).

Lo anterior se refuerza con la frase «cuando esté más vieja y no sirva pa' na'», que actúa como un recurso retórico de cosificación, en tanto un ser humano no puede reducirse a servir o no para algo, como lo haría alguna máquina o cosa. En esta línea, podría desprenderse que el discurso relaciona la carencia de actividad con la vejez, aunque Esperanza concreta dicha carencia en la figura de la «abuelita». En este sentido, «abuelita» sería una mujer sedentaria, sin movimiento, explicitándose dicha asociación por medio del ejemplo: «lugar de abuelitas pa' estar sentada sin hacer nada».

Además de la inactividad asociada a la «abuelita», el uso de este sustantivo alude a una retórica infantilista para caracterizar a otras mujeres, como también se aprecia en Adelaida:

Esto es como un jardín infantil, pero de abuelitas (Adelaida, 74 años, Organización 1).

Adelaida designa a las mujeres mayores como «abuelitas», ubicándose desde la indefensión y la pasividad. Lo refuerza con el morfema «itas» para provocar una emotividad asociada con la ternura y lo pequeño.

En el contexto chileno, un jardín infantil es una guardería para la primera infancia, donde los niños y niñas van a jugar y aprender. Por lo tanto, al plantear la analogía de la organización como un jardín infantil, Adelaida facilita la reproducción de un discurso edadista-viejista que infravalora el envejecimiento y la vejez femenina, posicionando a las mujeres mayores desde la pasividad, que a su vez, las hace proclives a sufrir mayores niveles de dependencia y desacreditación social (Coupland et al., 1991; Marsden y Holmes, 2014).

Paralelamente, existe un interdiscurso entre el edadista-viejista de la vejez femenina con el discurso heteropatriarcal, en tanto supone la heterosexualidad de una mujer mediante una descendencia (hijos e hijas), que también tendrían su propia sucesión (nietos y nietas). Por lo tanto, de estos discursos se desprende la ideología heteropatriarcal desde el edadismo-viejismo.

El segundo tipo de construcción discursiva de la vejez fisura la infantilización al tener como base la adultización: 
[abuelita] como que la palabra avejenta más a la persona, la tira más pa'abajo, como que creen que son inútiles $[. .$.$] entonces a mí me gusta por el nombre.$ Aquí todas nosotras nos decimos por el nombre [...] si somos adultas (Alma, 69 años, Organización 1).

Alma se posiciona respecto del uso de la palabra «abuelita» para designar a las mujeres mayores, aludiendo a lo problemático de su connotación social expresada en las expresiones «avejentar», «tirar más pa’abajo» y «ser inútil». En este sentido, avejentar implicaría hacer «más vieja» a una persona, que como se vio en citas anteriores, se relacionaría con la inactividad y la incapacidad, desprendidas de la afirmación «ser inútil». A esto se añade el chilenismo «tira más pa'abajo», que refiere a la acción de desalentar a una persona, por lo que, dentro de este contexto particular, al designar a una mujer como «abuelita» se reproduciría una significación socialmente negativa. La participante se resta de dicha reproducción, denominando a las mujeres mayores por sus nombres propios, lo que además es una práctica extendida en la organización. La designación por nombres es explícitamente asociada a la adultez: «si somos adultas».

Esta declaración de adultez también se produjo en otros contextos discursivos: Conversamos, nos reímos, tallas de doble sentido [risas], somos personas adultas con criterio formado, somos viejas ya (Teresa, 66 años, Organización 2).

Parte de las actividades cotidianas que realizan las mujeres mayores en las organizaciones es conversar y reír. Teresa utiliza la frase «tallas de doble sentido» para explicar que se ríen de las bromas de carácter sexual, rompiendo con la idea social de la asexualidad en la vejez. La expresa entre risas, mostrando una complicidad con las mujeres respecto del tema.

La adultización se desprende de: «somos personas adultas con criterio formado». Esto permite la creación de nuevas unidades discursivas en torno a la sexualidad, como mujeres adultas con agencia, no como niñas, ni como mujeres carentes de voluntad o consentimiento. Esto se refuerza con la frase «somos viejas ya», lo que otorga autoridad al argumento.

\section{REFLEXIONES FINALES}

Los discursos de las mujeres mayores sobre sus relaciones al interior de las organizaciones comunitarias autogestionadas refirieron a tres tópicos: a la relevancia de lo colectivo en la vejez femenina, a las prácticas de agencia y resistencia frente al control de la Iglesia y del Estado, y al hecho de ser mujeres viejas. 
En sus relatos podemos observar una fuerte agencia, que podría provenir de los conocimientos adquiridos para la subsistencia a lo largo de sus vidas. Vale decir, no solo podemos ver resistencia y subversión en algunos de sus actos, sino también aprendizajes vitales que sitúan sus existencias y adquieren trascendencia en lo colectivo (Navarro, 2017).

El dolor también estuvo presente en los relatos. Estos eran compartidos, lo que hacía más liviana su intensidad. Se cuidaban unas a las otras, fortaleciendo los vínculos entre ellas y resignificando la vejez, tradicionalmente vista como un período negativo de la vida. Se autodenominan «viejas» sin miedos ni eufemismos.

El discurso de ayuda mutua y sororidad estuvo presente en las dos organizaciones con las que trabajé. Las mujeres tejían redes sororas que se traducían en los cuidados mutuos. Así, a diferencia de lo plantado por Pérez-Sánchez et al. (2018), la sororidad se colocaba en práctica día a día. Los cuidados eran disfrutados, ya que no las limitaban en su actuar y fortalecían los lazos entre ellas. Podemos plantear que el apoyo mutuo es a la clase lo que la sororidad es al género.

La ayuda mutua no impidió la aparición del discurso heteropatriarcal y mercantil. No obstante, las redes de sororidad construidas a lo largo de la vida y las condiciones económicas las llevaban nuevamente a la participación colectiva de las organizaciones y la comunidad. Esto se opone a ciertos estudios que plantean que las dificultades económicas merman la participación social de las personas mayores (Repetti y Calasanti, 2017).

Por lo tanto, ¿qué nos mostraron las mujeres mayores? Que más allá de las dificultades y de las desigualdades acumuladas en sus biografias, las relaciones de sororidad entre ellas eran una fuente de fortaleza que les permitía significarse y significar al mundo de una manera diferente. Individualmente caminaban más rápido, pero juntas llegaban más lejos.

Por otro lado, pudimos evidenciar cómo el Estado chileno busca que las personas mayores se autogestionen, pero imponiendo un modelo que pueda controlar. Da la ilusión de «libertad de acción» bajo los muros que él mismo construye.

El control lo ejerce sobre la pobreza, mermando los derechos sociales y dando camino fluido al neoliberalismo. El lugar medular que tiene mercado y el patriarcado para su funcionamiento, hacen que el Estado sea antagonista del apoyo mutuo y de la interdependencia.

Finalmente, si queremos estudiar la vejez y el envejecimiento, desde una perspectiva feminista, es importante que las mujeres miremos a las diferentes 
vejeces femeninas como modelos con potencia, que construyen su agencia a partir de la ayuda mutua.

Como investigadoras de la vejez, tenemos que indagar en aquello pendiente del feminismo. No esperemos llegar a nuestras propias vejeces para estudiarlas; si no, correremos el riesgo de quedarnos desprovistas de modelos femeninos en los cuales mirarnos y reconocernos.

\section{REFERENCIAS}

Acosta, E., Picasso, F., y Perrotta, V. (2019). Cuidados en la vejez en América Latina. Los casos de Chile, Cuba y Uruguay. Fundación Konrad Adenauer.

Alonso, L. E. (1998). La mirada cualitativa en sociología. Una aproximación interpretativa. Fundamentos.

Arias, A., Lucero, C., Lores, C., Florín, C., Jorquera, F., Jofré, S. y Villegas, R. (2020). Peñalolen. Plan maestro de integración social $\left(\mathrm{N}^{\circ} 10\right.$; Documentos de Trabajo Del IEUT).

Cañas, S. (2018). Las mujeres indígenas y campesinas del sureste mexicano: agencia femenina a debate. Multidisciplinary Journal of Gender Studies, 7(2), 16341656. https://doi.org/10.17583/generos.2018.2776

Coupland, N, Coupland, J. y Giles, H. (1991). Language, society \& the elderly. Blackwell.

Denzin, N. y Lincoln, Y. (2005). Introduction. The discipline and practice of qualitative research. En N. Denzin y L. Yvonna (eds.), The Sage Handbook of Qualitative Research (pp. 1-13). SAGE.

Enríquez, R. (2014). Feminización y colectivización del cuidado a la vejez en México. Cadernos de Pesquisa, 44(152), 378-399. https://doi.org/10.1590/198053142873

Fairclough, N. (2008). El análisis crítico del discurso y la mercantilización del discurso público: las universidades. Discurso \& Sociedad, 2(1), 170-185.

Flores, R. M. y Garay, S. (2019). Calidad de vida y vejez masculina en México. Perspectivas Revista de Ciencias Sociales, 8, 380-392. https://doi.org/10.35305/prcs. v0i8.67

Freixas, A. (2008). La vida de las mujeres mayores a la luz de la investigación gerontológica feminista. Anuario de Psicologia, 39(1), 41-57.

Freixas, A., Luque, B. y Reina, A. (2012). Critical feminist gerontology: In the back room of research. Journal of Women \& Aging, 24, 44-58. https://doi.org/10.108 0/08952841.2012.638891 
García Dauder, S. (2003). Fertilizaciones cruzadas entre la Psicología social de la ciencia y los estudios feministas de la ciencia. Athenea Digital, 4, 109-150. https:// doi.org/10.5565/rev/athenead/v1n4.89

García, L. (2013). El barrio popular en Bogotá en las voces de sus protagonistas. Madres comunitarias y jardineras: 1980-2011, Usme y Ciudad Bolívar. Folios, 38, 121-140. https://doi.org/10.17227/01234870.38folios121.140

Garretón, M. (2012). Neoliberalismo corregido y progresismo limitado. Los gobiernos de la Concertación en Chile, 1990-2010. ARCIS.

Gómez-Rubio, C., Zavala-Villalón, G., Ganga-León, C., Rojas, W. y Álvarez, R. (2016). Jubilación en Chile: Vivencias y percepciones de mujeres jubiladas por el sistema privado de pensiones. Psicoperspectivas. Individuo y Sociedad, 15(3), 112-122. https://doi.org/10.5027/psicoperspectivas-Vol15-Issue3-fulltext-825

Hooyman, N., Ray, R., Browne, C. y Richardson, V. (2002). Feminist Gerontology and the Life Course. Gerontology \& Geriatrics Education, 22(4), 3-26. https://doi. org/10.1300/J021v22n04

Huenchuan, S. (2018). Envejecimiento, personas mayores y Agenda 2030 para el Desarrollo Sostenible: perspectiva regional y de derechos humanos. En Libros de la CEPAL. Naciones Unidas. https://doi.org/10.18356/19532890-es

Ilustre Municipalidad de Peñalolén. (2021). Adulto Mayor. https://www.penalolen.cl/ adulto-mayor/

Iñiguez-Rueda, L. (2003). El lenguaje en las ciencias sociales: fudamentos, conceptos y modelos. En L. Iñiguez-Rueda (ed.), Análisis del discurso. Manual para las ciencias sociales (pp. 43-82). UOC.

Instituto Nacional de Estadística, C. (2017). Resultados CENSO 2017. http://resultados. censo2017.cl/Region?R=R13

Irarrázaval, I., Streeter, P. y Salas, I. (2018). Comprometidos con Chile: la contribución de las organizaciones de la sociedad civil a la infancia y las personas mayores. Pontificia Universidad Católica de Chile.

Lagarde, M. (2006). Pacto entre mujeres sororidad. Pacto de Género, 1-12. http:// pmayobre.webs.uvigo.es/textos/marcela_lagarde_y_de_los_rios/sororidad.pdf

León, A. y Montenegro, M. (1999). Análisis del concepto de autogestión a la luz de una experiencia comunitaria en el Barrio «Niño Jesús», Caracas, Venezuela. Psykhe, 8(1), 179-183.

Leyra, B. y Roldán, E. (2013). Reflexiones feministas sobre las mujeres mayores, el envejecimiento y las políticas públicas. Aproximaciones al caso español. Ex Aequo, 28, 103-117. 
Lois, I. (2020). Feminismos latinoamericanos en perspectiva colonial e interseccional. Margen, 99, 1-9.

Mahmood, S. (2005). Politics of Piety. The islamic revival and the feminist subject. Princeton University Press https://doi.org/10.2307/j.ctvet00cf

Majón-Valpuesta, D., Pérez-Salanova, M., Valverde, P. R. y Molina, A. H. (2021). Agencia y participación en la vejez de la generación baby boom: Reclamación de espacios alternativos. Athenea Digital, 21(1), 1-24. https://doi.org/10.5565/ rev/athenea.2696

Marsden, S. y Holmes, J. (2014). Talking to the elderly in New Zealand residential care settings. Journal of Pragmatics, 64, 17-34. https://doi.org/10.1016/j. pragma.2014.01.006

Martín-Crespo, M. C. y Salamanca, A. B. (2007). El muestreo en la investigación cualitativa. Nure Investigación, 27, 1-4. http://www.nureinvestigacion.es/ FICHEROS_ADMINISTRADOR/F_METODOLOGICA/FMetodologica_ 27. pdf

Méndez, N., y Vallota, A. (2006). Una perspectiva anarquista de la autogestión. Revista Venezolana de Economía y Ciencias Sociales, 12(1), 59-72.

Ministerio de Desarrollo Social (2017). Adultos mayores. Síntesis de resultados. CASEN. En Encuesta de Caracterización Socioeconómica Nacional. http:// observatorio.ministeriodesarrollosocial.gob.cl/storage/docs/casen/2017/Resultados_Adulto_Mayores_casen_2017.pdf

Navarro, S. (2017). Saber femenino, vida y acción social. Dar a luz experiencias creadoras. CCS.

Organización Mundial de la Salud. (2021). Envejecimiento y ciclo de vida. https://www. who.int/ageing/about/facts/es/

Paura, V. y Zibecchi, C. (2014). Mujeres, ámbito comunitario y cuidado: consideraciones para el estudio de relaciones en transformación. La Aljaba, 18. https://doi. org/10.17141/iconos.50.2014.1433

Pérez-Sánchez, L., Rábago-De Ávila, M., Guzmán-Ortiz, M. y Zamora-Pérez, R. de J. (2018). Sororidad en los procesos de envejecimiento femenino. Diversitas: Perspectivas en Psicología, 14(1), 13-26. https://doi.org/10.15332/ s1794-9998.2018.0001.01

Repetti, M. y Calasanti, T. (2017). «Since I retired, I can take things as they come. For example, the laundry»: gender, class and freedom in retirement in Switzerland. Ageing \& Society, 38(8), 1-25. https://doi.org/10.1017/S0144686X17000174

Thumala, D., Arnold, M., Massad, C. y Herrera, F. (2015). Inclusión y exclusión social de las personas mayores en Chile. 
Valles, M. (1999). Técnicas cualitativas de investigación social. Síntesis.

Van Dijk, T. A. (2009). Critical discourse studies: A sociocognitive approach. En R. Wodak y M. Meyer (eds.), Methods of Critical Discourse Analysis (pp. 62-86). SAGE.

Vera, J. y Ceballos, Z. (2021). Autogestión comunitaria: una apuesta para la investigación y la intervención. En Acciones de psicología comunitaria desde los escenarios académicos, comunitarios e investigativos (pp. 22-41). UNAD.

Wodak, R. (2003). De qué trata el análisis crítico de discurso (ACD). Resumen de su historia, sus conceptos fundamentales y sus desarrollos. En R. Wodak y M. Meyer (eds.), Métodos de análisis crítico del discurso (pp. 17-34). Gedisa.

Yuni, J. A. y Urbano, C. A. (2008). Envejecimiento y género: perspectivas teóricas y aproximaciones al envejecimiento femenino. Revista Argentina de Sociología, 6(10), 151-169.

Zibecchi, C. (2013). Organizaciones comunitarias y cuidado en la primera infancia: un análisis en torno a las trayectorias, prácticas y saberes de las cuidadoras. Trabajo y Sociedad, 20, 427-447. 